\title{
A CONCEPTUAL PRACTICE AND EFFECTS IN RESILIENCE RISKS AMONG ADOLESCENCE
}

\author{
Ganesan Shanmugavelu' ${ }^{1}, \mathrm{PhD}$ \\ Senior Lecturer, \\ Institute of Teacher Education Ipoh Campus, \\ Malaysia
}

\author{
Amuta Arumugam ${ }^{2}$ \\ Master Trainee Counselor, \\ Universiti Utara Malaysia
}

\author{
Manimaran Armugam \\ EdD Candidate, \\ Sultan Idris Education University, \\ Malaysia
}

Article DOI: https://doi.org/10.36713/epra5991

\begin{abstract}
The aim of this study is to discuss the models of resilience protective, challenge and describe how resilience differs from related concepts. The key terms are discussed about methodological issues, and explore implications for the profession by focusing on adolescents to overcome the negative effects of risk exposure. However, to bridge the gaps in current understanding, involves facilitation of skill acquisition via strengthening processes. An overview of this resilience research related to adolescent substance use, violent behaviour, and social risk behaviour. Consider the findings specifically emphasis on the developmental period of adolescence and forms the basis of a framework that allows an individual variance in resilience, the identification of both neurobiological and psychosocial targets for prevention therapeutic interventions. This study enhances intervention protective factors in adolescent to offset these vulnerabilities and thus promote the health of adolescents. The objective of coping reactions is fundamental to the enduring effects of violence exposure on their psychosocial development and functioning. Finally, this study illustrates the manner in which coping efforts can support resilience among adolescent stage exposed to violence and suggest new directions for research and preventive intervention aimed at optimizing outcomes for adolescent at risk of exposure.
\end{abstract}

KEYWORDS : Resilience Risk, Protective Factors, Social Practice, Attitude, Behaviour

\section{INTRODUCTION}

This research explains about the resilience process of overcoming the negative effects of risk exposure, coping successfully with traumatic experiences, and avoiding the negative trajectories associated with risks. Basically, the resilience presence of both risks and promotive factors that either help bring about a positive outcome or reduce or avoid a negative outcome. In fact, people will experience twists and turns as of everyday challenges traumatic events with more lasting impact such as loss of a loved one, a life-altering accident, or a serious illness. Each adjustment affects people differently, bringing a unique flood of thoughts, strong emotions, uncertainty and the ability to learn from ordinary not extraordinary. The lifespan maturity affected by maltreatment and other serious forms of adversity such as trauma, tragedy, threats, or significant sources of stress, family and relationship problems, health problems, or workplace and financial stressors. It also involves "bouncing back" from these difficult experiences which involve profound personal growth due to a move away from 'deficit models of illness and psychopathology. However, resilience theory, concerned with risk exposure among adolescents, it emphasizes on understanding healthy development in spite of risk exposure on the strengths rather than weaknesses. The complexities of resilience defining what appears to be the relatively simple concept that are widely recognized, especially within the behavioural sciences perhaps, there are many aspects of life that can control, modify, and grow with. Almost more resilient not only helps get through difficult circumstances, it also empowers people to grow and 
even improve life along the way. That's the role of resilience.

The dynamics of resilience framework approach to address a health risk behaviour that is amenable to early health-promoting interventions also across the lifespan, its role in a healthy managing practice and changes in cognitive functioning. Adolescent's experiences with violence been linked with a range of behavioural and mental health difficulties, including posttraumatic stress disorder and aggressive behaviour. Resilience has been conceptualized as a process involving an interaction between both risk and protective processes, internal and external to the individual, that act to modify the effects of an adverse life event (Rutter, 1985, 1999). Resilience in the adolescent reflects a deeper problem within the field of resilience, that is, the lack of a unified theory capable of guiding more structured and empirical methodologies for developing the construct (Luthar, Cicchetti, \& Becker, 2000). The progress of an understanding, a way of thinking, resilience can be elements of the construct, and suggesting different approaches to measurement. It can be defined as an outcome characterized by particular patterns of functional behaviour despite risk. Another assumption, resilience defined as a dynamic process of adaptation to a risk setting that involves interaction between a range of risk and protective factors for the individual to the social.

\section{a) Method of Designing Planning Strategic}

This study illustrates the strategic planning provides a structured approach for determining what goals individuals should pursue to accomplish his/her mission over the medium-term and long-term, and how it can most effectively achieve their goals. Especially, what enabled and hindered in adopting and embedding the new approach in their life. Hence, the roadmap to resilience is considered to involve emotional distress that connection with major trauma or adversity in their lives commonly experience with emotional stress. While on the opposing, resilience involves behaviours, thoughts, and actions that anyone can learn and develop. Ultimately, in early stage, adolescence is a time rapid development and change an important consequence which include the adoption of risky behaviour. The link between resilience and development seems to reflect the fact that the processes are interactive and endure over time. Because of their apparent sense of invulnerability risk and danger, many adolescents participate in risky behaviour Rutter (1993). Alternative meaning like building a muscle, increasing resilience takes time and intentionality. Gradually, the basic elements correlate their healthy thinking, and meaning that will empower people with resilience to withstand, learn from difficult pathway and traumatic experiences. To increase capacity for resilience to weather and grow from the difficulties, the below strategies explain an importance stages for improvement.

\section{- Prioritize relationships}

Bonding with empathy and understanding people can remind that impacted person, not alone in the midst of difficulties. Concentrating on a retrieving of trustworthy and compassionate individuals who validate feelings will support skill of resilience. The upsets, distress and traumatic outcome may lead some people to isolate themselves, therefore it's important to accept help and support from those who care about, try to prioritize genuinely connecting with people who concern about.

\section{- Factors that contribute}

Individuality traits that help them remain unflappable in the face of challenge, however, these behaviours are not just inborn traits found in a select few individuals. Psychologically a strong person tends to have the support of family and friends who help bolster them up in times of trouble. Other factors associated with resilience include:

i. Holding positive views of themselves and their abilities

ii. Possessing the capacity to make realistic plans and stick to them

iii. Having an internal locus of control

iv. Being a good communicator

v. Viewing themselves as fighters rather than victims

vi. Having high emotional intelligence and managing emotions effectively

\section{- Reframe thoughts}

Realistically resilient people are able to look at negative situations, but in a way that does not blame or brooding over what cannot be changed. As a replacement viewing adversity as insurmountable, focus on looking for small ways that can tackle the problem and make changes that will help. Aiming on the positive, manageable mindset so that get out of a negative way of thinking, also approach to learning how to better cope with challenges. Inspire to think about challenges in more positive, instead of getting stuck in a loop of negative emotions, learn to see an opportunity to challenge themselves and develop new skills 


\section{- Focus on What Can Control}

It can be easy to get overwhelmed when faced with crisis or problems that fell far beyond their control. Instead of challenging some ways to overcome the situation thus, try focusing on situations that control to take realistic steps to help improve. No doubt how small the steps, in fact, there is a way of improving the sense of control and resilience. Resilience is an important ability to practice with resilience-building skills in daily life challenges. Establishing a positive outlook with strong support system, and taking active steps to make things better.

\section{- Seeking help}

Getting help when need building resilience is crucial and the kinds of strategies at that time, probably they might get stuck or have difficulty making progress on the road to resilience. In fact, this situation can get psychologist assist people in developing an appropriate strategy for moving forward. It is important to get professional help if feels the situation are unable to function as well as would like or perform basic activities of daily living traumatic or other stressful life experience.

\section{b) Design of Hypothesis Method}

The challenge for the field is to develop significant theories of resilience that can ultimately inform best practice interventions promoting positive developmental outcomes in adolescence in listed hypothesis.

$\begin{aligned} \text { i. } & \text { Positive temperament } \\ \text { ii. } & \text { Robust neurobiology } \\ \text { iii. } & \text { Responsiveness to others } \\ \text { iv. } & \text { Pro-social attitudes } \\ \text { v. } & \text { Attachment to others } \\ \text { vi. } & \text { Academic achievement } \\ \text { vii. } & \text { Planning and decision making } \\ \text { viii. } & \text { Tolerance for negative affect } \\ \text { ix. } & \text { Self-efficacy / Self-esteem } \\ \text { x. } & \text { Foundational sense of self } \\ \text { xi. } & \text { Internal locus of control } \\ \text { xii. } & \text { Sense of humour } \\ \text { xiii. } & \text { Hopefulness } \\ \text { xiv. } & \text { Strategies to deal with stress } \\ \text { xv. } & \text { Enduring set of values } \\ \text { xvi. } & \text { Balanced perspective on experience } \\ \text { xvii. } & \text { Malleable and flexible } \\ \text { xviii. } & \text { Fortitude, conviction, tenacity, and resolve } \\ \text { xix. } & \text { Parental warmth, encouragement, assistance } \\ \text { xx. } & \text { Cohesion and care within the family } \\ \text { xxi. } & \text { Close relationship with a caring adult } \\ \text { xxii. } & \text { Belief in the child } \\ \text { xxiii. } & \text { Non-blaming } \\ \text { xxiv. } & \text { Talent or hobby valued by others }\end{aligned}$

Overwhelmingly, the findings point in this study is an importance of promoting positive behaviour, identifying risks, and including factors such as family, culture and community resources in intervention or developmental (2002) and Printz et al (1999).

\section{c) Analyse and interpret data information}

Considering resilience as a dynamic process, one approach to measurement is to develop a capable assessing range of psychosocial resources, skills, capabilities and talents available to an individual to negotiate adversity. Their broader social environment, resources may be assessed within the individuals, their family and peer networks. The contained of the assumption in this approach is greater the range of resources an individual has, the more likely the individual will be capable of mounting an adaptive response to any life crisis (Constantine et al., 1999). Specifically, be more useful to accept specific definitions of resilience, such as social resilience, academic resilience or emotional resilience as these may yield more detailed insights into the development (Luthar et al. (1993). Consuming a positive self-concept, individuals well set up to maintain competence demonstrate a resilient outcome under a range of seemingly different kinds of adversities. In the same way, the self-concept may be well developed in one area, but not in another, making for a resilient outcome in the former but not the latter. Effective intervention would result in the cultivation of a few key attitudes and life approaches. The measurement provides the potential to better explore the nature of resilience and the range of interventions designed to develop resilience.

\section{d) Implication to Positive Reframing Development}

The art of learning resilience explain that people can train their brain to be more resilient by harnessing their stressors and using them to their advantage. Basically, people who endured enormous amounts of stress from war, assault, and disasters as well as other less traumatic events and ultimately thrived. Here is some improvement step "prescription" to re-train brain into becoming more resilient.

i. Keep a positive attitude. Even though, looks too straightforward, keeping a positive attitude is key to deflect stressors. It takes time for some difficult people, a large part of how optimistic are determined by genetics and the chemistry of brain's reward circuits. In a way to restructure brain's response to stress is to stop pessimistic thoughts in their tracks and similar to recognize situation in control of whether the glass is half-empty or half-full.

ii. Reframe stressful thoughts. If the root of stress can be linked to a particular event, try reframing the event and realizing 
that failure is essential for growth. Optimism the reframing, assimilating, accepting and recovering from by learning to "alter the perceived value and meaningfulness".

iii. Develop moral compass. Selflessness is strongly related to resilience, and strengthening set of core beliefs can help. However, recognize a strong correlation between faith and religious or spiritual beliefs and resilience.

iv. Find a resilient role model. The synthetic model is a powerful mode of learning. The characteristics models are so important that their values can influence own values through psychological imprinting and find role models that can look up to in times of stress.

v. Face fears. Fear is normal, so in that case, don't be ashamed of being afraid. Fear can be a powerful tool that can increase individual self-esteem by helping learn and practice skills necessary to overcome stress.

vi. Develop active coping skills. Regardless how painful it may be, try actively coping with stressors instead of withdrawing and surrendering to them. Utmost resilient people use active rather than passive coping skills like minimizing appraisal of the stressor, creating positive statements about themselves, and actively seeking support from others.

vii. Establish and nurture a supportive social network. Building a safety net of close relationships with friends or organizations can boost personal emotional strength during times of stress. Thus, feel the validation of helping others deal with their own stressors.

viii. Prioritize physical wellbeing. Consistent exercise is one of the keys to cleansing the mind of stress, and with good reason. Remaining routine physical activity has been linked to improvements in mood, cognition, regulation of emotion, immunity, and overall self-esteem. Physical workout may trivial when you're faced with mounting stress and anxiety, so try to think of it as a welcome reprieve rather than as yet another task to be completed. Again, it's all about framing the mindset.

ix. Train your brain. Changing the way thoughts works may seem like a daunting task, but with a little self-discipline it can be accomplished through regular and rigorous training. Take a challenge to the practice of working to build emotional intelligence, moral integrity, and physical endurance can help deflect stressors to all aspects of brain training.

x. Play to strengths. Recognize, utilize, and grow a signature character strength to actively prepare for difficult and stressful situations. Encourage to think about challenges in a more positive, hopeful ways to strength an opportunity to challenge and develop new skills.

xi. Support build a strong social network. Resilience among adolescent built a strong foundation supportive and loving relationships with others. Make sure they are surrounded by people who they feel comfortable to approach and who they know will support them. Inclusive friends, family, teachers, mentors, sport's coaches, psychologists. Perhaps, these people don't make the issue go away, they provide support, understanding and may be able to give suggestions on ways to move forward.

xii. Self-Involvement. Developing a sense of belonging is important for a teenagers' selfesteem and sense of identity. This encouragement will advantage them to form positive and supportive connections, and will give them opportunities to develop skills such as teamwork, conflict resolution and cooperation, and will give them a sense of belonging. Inspiring people to have dreams and "bucket lists" will also help them having a sense of purpose and some things to focus on in the future if faced with challenges in the short term.

\section{e) Goal and Target of Intervention}

Resilience in positive psychology refers to the ability to cope with whatever life throws to individual, some people are knocked down by challenges, but they return as a stronger person more steadfast than before. Their mechanisms through challenges by using personal resources, strengths, and other positive capacities of psychological capital like hope, optimism, and self-efficacy. Overcoming a crisis via resiliency is often described as "bouncing back" to a normal state of functioning perhaps being resilient is also positively associated with happiness. This category of person in the relationship, play big roles in the development of resilience. During positive relationships occur, welladjusted and rule-abiding behaviours are valued influence a strong positive effect on resilience levels. However, the characteristics of resilience include cognitive skills, personality differences, problemsolving ability, self-regulation, and adaptability to stress. During their adult relationships and supportive environments, they can develop tools that subconsciously improve their psychological 
resilience and aforementioned skills with key protective individual factors:

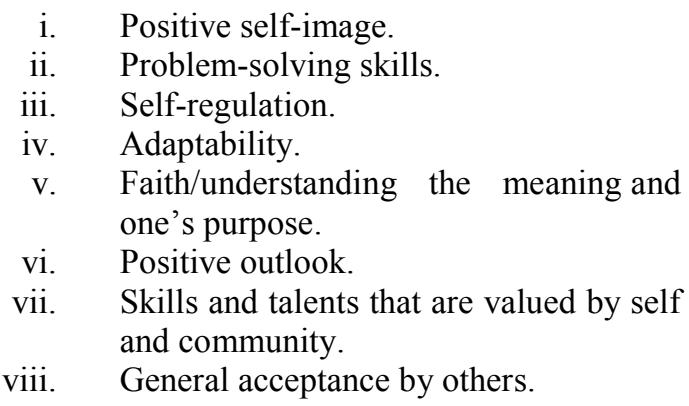

As a simulation, people who are resilient might exhibit a positive attitude that guides them through the obstacle and change their negative failure identity to something helpful instead, as well feedback and motivation, they able cope to get better and "fail forward." Getting in touch with other people, helping them, and establishing positivity are important steps in learning resilience.

\section{f) Developing a Mindset That Fosters Success}

Personal experienced development success and lifestyle exposing glory the goal achievement as such, it is a key point that develops learning to foster a sense of resilience within their inner self to ensure overcome these setbacks to rise a greatness. Below practice are series of tools designed to help cultivate resilience and prepare for the roadmap ahead.

\section{- Practice Your ABC's}

This research illustrates the ABCDE model that allows people to deconstruct a specific "problem" and understand how their "beliefs about what happened" caused them to feel a certain way, not the event itself. This creates a greater level of awareness about own reactions, so it works to have the skill sets needed for a healthier response to adversity. These steps help build resilience by recognizing unfavourable thought patterns, finding the true reason behind the emotions, recognizing the negative impact of these emotions, and learning to challenge them. The model is composed of 5 steps:

$\begin{array}{ll}\circ & \text { Adversity; } \\ \circ & \text { Beliefs; } \\ \circ & \text { Consequences; } \\ \circ & \text { Disputation; } \\ \circ & \text { Energization. }\end{array}$

- Identify and Leverage the Strengths

Mostly people don't know the level of their strengths and characteristic strengths is a good way to experience their competence. Ultimately, it moves smoothly whereby people often take it for granted and don't recognize it as a major strength. There were multiple dimension strengths are associated with happiness, which in turn helpful state of mind to become more resilient. A significant consciously embracing in daily life and mindfulness leads to increase happiness to produce authentic pleasure and abundant gratification. Moreover, the moment times are tough, it's easy to lose hope and optimism, indirectly they need to know their strengths, especially when life gets tough. Whereby, individual strengths help with greater vitality and motivation to a clearer sense of direction, higher self-confidence, productivity and a higher probability of goal attainment (Clifton \& Anderson, 2001-2; Hodges \& Clifton, 2004; Peterson \& Seligman, 2004). Strengths serve well in times of darkness, as well times light, so this is the moment to start knowing own valuing.

\section{- Remain Positive}

Ignoring the problem doesn't mean being a positive thinker, instead it means understanding that setbacks are transient and that possess the skills and abilities to combat the challenges that are being faced. Encourage to use positive self-talk such as "I've got this" or "I can manage this situation", I know I can" and encourage them to remain hopeful and positive that things will improve.

- Esteem Building a Positive Self-Efficacy Having a good self-efficacy plays an important role in coping with stress and recovering from difficult events. Remind of their strengths and abilities, and focus on how they can use these skills to solve their problems. Ensure surrounded by people who promote their self-esteem and have positive beliefs in their abilities. Almost adults are often uncertain about themselves, so having people encouraging them and pointing out their strengths goes a long way in giving them a boost.

\section{- Explore all Options}

Before giving suggestions when they are faced with a challenge, encourage them to problem solving by own self. It is an important skill to learn how to solve problems and will assist in all aspects of everyone's life.

○ Ask: what is the problem?

○ Ask: what are the options / possible solutions?

- What are the pros / cons and consequences of each option?

- Make a decision

- Do and review

- Nurture own-self

- Create Goals

Encourage adolescent to create and preserve their goals to overcome problems. Whereby some approaches, such as brainstorming and problemsolving skills may assist their ability in coping skills. It is also important to maintain longer term life goals as well. In case they have a future strategy that they want to achieve, subsequently it may help them stay focused on what is important and to move past difficult experience situations they faced immediately. 


\section{- $\quad$ Easy Going}

Approach them to be a flexible and adaptable person, as this will assist them to manage unexpected situations if they arise. If they faced with changes and challenges, encourage them to step back and think about how they need to adjust their expectations and plans to go in a new direction. This new direction may be a positive things and resilient people can adapt and thrive with new opportunities. Basically, resilience is important in order to overcome and thrive following challenging life events. It is habitually that require long-term consistent commitment to develop this skill, but has the potential to assist an individual to live a happy and fulfilled life despite its challenges.

\section{g) Improvement Through Therapy}

This research illustrates the counselling process for resilience coaching have the same focus building someone's personal assets, therefore to build skills in resilience, praise in the process of growth must be abundant (Kamins \& Dweck, 1999). Knowing that resilience as the mental processes and behaviours that people use to protect themselves from the harmful effects of stressors, hence some people are naturally resilient. Almost we notice resilience like planning for an oncoming storm that helps to diffuse the power of the storm itself. The methodology in facilitating the client or patient focus on what has worked well for them in the past, and a baseline for their resilience skills can be established.

Therapeutic setting, the benefits of counselling include building resilience that will likely draw from discussing past experiences in terms of perseverance. By assisting their focus on the process that they previously used to overcome adversity, it may facilitate them better understand the skills that already exist within them. However, this manner emphasis builds their confidence and readiness for the inevitable adversities that they will likely face in their lifetime. Whereby therapeutic setting may have higher risk factors like anxiety, depression, negative affect, perceived stress, and PTSD (Lee, J.H., et al., 2013). Bottleneck a closer understanding of individual, family, and social factors and their integration with protective factors in resilience is vital to healing. Hence, counsellors have to be very aware of their process for keeping their patients safe from re-experiencing a trauma.

\section{i. Tools for Fostering Resilience}

Finding subjective growth in connection to these protective factors is highly recommended, therefore protective factors necessary for building resilience (Masten et al. 1990). For each one of the following factors listed tools are recognizing can be used to foster resilience clients. Development strategy allows the person for more continue growth, especially lead to self-awareness takes intentional work and practice through mindful and deliberate practices. The factors necessary for building resilience a foundation in cognitive practices that allow for an important aspect of mindfulness and self-acceptance to flourish.

- life satisfaction

- optimism

- $\quad$ positive affect

- $\quad$ self-efficacy

- $\quad$ self-esteem

- $\quad$ social support

\section{ii. Life Satisfaction}

This study also elaborated the gratitude invading every area of life with heartfelt authenticity will help move toward a more satisfying view of life, including a gratitude practice in life can improve wellbeing (Nelson, 2009). It must be with the lightest touch that one embraces gratitude with any positive emotion. Deciding to practice less routine, but be more aware of its presence in life and cultivate that attitude of gratitude. Other optional way is to increase life satisfaction by finding meaning and purpose. This way will continually offer a compassionate quality of life and learning where to increase growth life satisfaction.

iii. Optimism

A realistic development in an optimistic explanatory style is a skill that anyone can grow to foster increased resilient person that consuming a flexibility in how explain outcomes is a skill that can be built with intention. A person's ability and more personal effort tend to move people in the direction of action rather than self-defeating and depressive explanations. Identity tool that help improve the presence of a realistic, optimistic explanatory style is reframing. By coping better with stress and avoiding unhealthy behaviours, they are able to improve their health, well-being and practice selfcompassion regularly. Most people can quickly identify what they don't want. Reframing into a realistic, optimistic explanatory would be into phrases like, "I am cultivating healthy habits," or "I am taking action toward building a healthy lifestyle." Self-kindness, an understanding of shared humanity, and improvement in mindfulness can counter the effects of compassion fatigue (Neff, 2020).

\section{iv. Self-efficacy}

In this research how one attributes success is an important area to explore when attempting to eliminate self-efficacy. When person attributes growth to personal effort instead of globally attributing to a character, efficacy is allowed to flourish. Results show that positive and negative affect influences a person's expectations, estimates of successes, self-evaluation, and goal setting (Wright, \& Mischel, 1982). A technique to establish attribution focus is a mastery memory exercise. Gradually allow self-attribute success to the consistent effort required for mastery, and celebrate 
how effective the person in building those successes. Stacking a successful habit is another tool that one can use to build self-efficacy. Start with a goal, then think backward from that goal to the simplest habit a person could adopt that would move toward that goal. Make that simple habit consistent over a period of time till simple change is well established, stack a new habit on top of the first. Consciously track the consistent change over time.

\section{v. Self-esteem}

Basically, significant core values and stepping into daily values give a foundation for their "sociometer" (Leary, M.R., \& Baumeister, R.F., 2000). To appraise one's value requires a clear personal lens and getting crystal clear on a personal set of values is a first step in building self-esteem (Leary, M.R. \& Baumeister R.F., 2000). Basically, interact and intertwine the value with other human beings, value need not be disrupted by those interactions. To know what value about self, then makes interacting with others easier. It allows to lead in any interaction already holding in high esteem of value. Ultimately, a great way to build self-esteem is to find a new area of growth and master a new skill. Performing mindful speaking, for instance, is a great skill to develop to build self-esteem. Anxiety tends to interfere with social interaction, disrupting ability to hear the other person in any conversation. By increasing ability to listen to others actively, then improve mindful speech. Practicing with every person meet gives us ample opportunities to grow the skill, making conversations more fun.

\section{vi. Social Support}

Boosting friendships are one way to increase resilience thus, don't be concerned about being the most popular person on the block. Enrich and nurture close friendships to improve social support and more positive relationships. Either wat it is through volunteerism, schools, or places of worship, getting involved in supporting others helps everyone. People who are involved in altruistic endeavours live longer and have better health (Schwartz et al., 2008). However, an impactful technique for helping a client improve their social wellbeing is by teaching ways to practice compassion. The roadmap be active it, have a patient focused on a relationship where they feel compassion easily, like with a pet or a child. Recognize them, then try to shift into having that same outlook for others that may challenge them.

\section{vii. Person focused approach}

This study illustrates to identify comparative individuals from within similarity high levels of adversity, who show patterns of good or poor adaptation, simultaneously assessed by multiple criteria, so as to identify the aspects that might lead to risk or be assets. This methodology is often used to classify the proportion who may be determined resilience. For example, in examining the characteristics of youths living in poverty, (Buckner et al.60) resilience as the presence of competences, adaptive functioning and lack of significant mental health problems. Psychologists focused on identifying the personality traits responsible for the positive outcomes that subset of adolescents. Whereby an assumption that resilience was created by some static internal quality of an individual. Over time, psychologist realized that resilience is more than just personality traits. Generally, the capacity in resilience is a dynamic process adapting successfully to disturbances that threaten an adolescent's function and development.

In a dynamic process resilience is more protective factors come from outside of an individual, rather than resiliency or resilient child because the latter implies it is only a quality of the individual. Perhaps, resiliency is a simple concept bouncing back after adversity. But defining resilience, as well as analysing and understanding it, is a complex subject in psychology. However, there are many resilience models have been developed and the ongoing neuroscience studies have contributed to the understanding. Despite the research complexity, one thing is obvious and simple for parents to build resilience, we have to do our part to connect with them and provide good parenting. In this theory the strengths able to adapt the difficult situations in life, this approach be taken as the protective factors against stressful situations and help them in coping with these difficulties. Adaptive and elaborative in their own thoughts with ultimately leads to an individual being more resilient and therefore it has a positive relationship. Refer to Luthar there are three types of protective factors and those are:

\section{Key elements of theory:}

i. Protect-stabilizing (despite the increasing risk, attribute gives stability to competence)

ii. Protective-enhancing (engaging stress and increasing confidence within self)

iii. Protective but reactive (general advantages but not with high-stress levels)

\section{CONCLUSION}

Although the term resilience has gained great popularity, this study has emphasized how resilience has been investigated both as an outcome of adaptation and as a process of adaptation. Investigations of resilient outcomes have focussed on the protective risk of functionality (e.g. behavioural, relationship, health risk, and social competence) despite the risk to the contrary. Whereby the process of adaptation has necessitated assessment of a range of risk and protective mechanisms that act in concert and over time to mediate the effects of a risk setting. The subsequent common sub-structure involving assessment of the risk setting, the interaction of risk and protective process, and resultant adaptive outcomes. Gradually the key identity dimensions of the concept of resilience, concurring developed the 
measurement that focus on assessment of the range of protective processes to the outcome of adaptation. This resilience research is closely linked with intervention in that protective process can inform the development of targeted intervention. While both risk reduction and resilience development approaches share the common goal of prevention, the emphasis of each approach is somewhat different. Hence, resilience-based approach emphasizes the building of skills and capacities that facilitate successful negotiation of high-risk environments. However, risk of reduction approach, on the other hand has emphasized removing or avoiding factors or processes implicated in the development of problematic outcomes (e.g. behavioural experimentation).

Basically, in this research relates to intervention, the context in which people live could be altered, the services and treatment received can be improved and individual assets possible be enhanced so as to enable a better chance for health and wellbeing, even when they faced with substantial risk and adversity. Significantly, the complex interplay between these layers should be recognized and the underlying processes explored. Thus, the person experiencing persisting, chronic adversities, psychopathology can be averted providing that the individual is able to draw on a range of resources within themselves and their immediate environment, and that the wider environment is also supportive to enhance the opportunity for positive adaptation.

\section{REFERENCES}

1. Buckner JC, Mezzacappa E, Beardslee WR. Characteristics of resilient youths living in poverty: The role of self-regulatory processes. Dev Psychopathol 2003; 15: 139-62.

2. Cavanaugh, M.A., Boswell, W.R., Roehling, M. V., and Boudreau, J. W. (2000). An Empirical examination of self-reported work stress among US managers, Journal of Applied Psychology, 85, 65-74.

3. Campbell-Sills L, Cohan SL, Stein MB. Relationship of resilience to personality, coping, and psychiatric symptoms in young adults. Behav Res Therapy 2006; 44: 585-99.

4. Constantine, N., Bernard, B., \& Diaz, M. (1999). Measuring protective factors and resilience traits in youth: The health kids resilience assessment. Unpublished Work.

5. Cove, E., Eiseman, M., \& Popkin, S. J. (2005). Resilient children: Literature review and evidence from the HOPE VI Panel Study. Washington, DC: The

6. Hodges, T.D., \& Clifton, D.O. (2004). Strengthsbased development in practice. In P. A. Linley \& S. Joseph (Eds.), Positive psychology in practice (pp. 256-268). New Jersey: John Wiley \& Sons, Inc.

7. Harkin, B., Webb, T.L., Chang, B.P.I., Prestwich, A., Conner, M., Kellar, I., Benn, Y. and Sheeran,
P. (2016). Does Monitoring Goal Progress Promote Goal Attainment? A Meta-Analysis of the Experimental Evidence. Psychological Bulletin, 142 (2), 198-229.

8. Kamins, M. L., \& Dweck, C. S. (1999). Person versus process praise and criticism: Implications for contingent self-worth and oping. Developmental Psychology, 35(3), 835847.

9. Leary, M. R., \& Baumeister, R. F. (2000). The nature and function of self-esteem: Sociometer theory. Advances in Experimental Social Psychology, 1-62.

10. Luthar, S. S. (1993). Annotation: Methodological and conceptual issues in research on childhood resilience. Journal of Child Psychology and Psychiatry, 34, 441-453.

11. Luthar, S. S., Cicchetti, D., \& Becker, B. (2000). The construct of resilience: A critical evaluation and guidelines for future work. Child Development, 71(3), 543-562.

12. Masten AS, Powell JL. 2003. A resilience framework for research, policy, and practice. See Ref. 63a, pp. 1-28

13. Masten, 2001 A.S. Masten Ordinary magic: Resilience processes in development American Psychologist, 56 (3) (2001), pp. 227-238.

14. Masten, A.S., Best, K.M., \& Garmezy, N. (1990 Resilience and development: Contributions from the study of children who overcame adversity. Development and Psychopathology, 2(4), 425-444.

15. Nelson, C. (2009). Appreciating gratitude: Can gratitude be used as a psychological intervention to improve individual wellbeing? Counselling Psychology Review, 24(3-4), 38-50.

16. Rutter M. 1985. Resilience in the face of adversity. Protective factors and resistance to psychiatric disorder. Br. J. Psychiatry 147:598611

17. Rutter, M. (1985). Resilience in the face of adversity: Protective factors and resistance to psychiatric disorder. British Journal of Psychiatry, 147, 598-611.

18. Rutter, M. (1999). Resilience concepts and findings: Implications for family therapy. Journal of Family Therapy, 21, 119-144.

19. Rutter, 1987 M. Rutter Psychosocial resilience and protective mechanisms American Journal of Orthopsychiatry, 57 (3) (1987), pp. 316-331.

20. Resnick, M. (2000). Protective factors, resiliency and healthy youth development. Adolescent Medicine: State of the Art Reviews, 11(1), 157164.

21. Schwartz, C.E., Keyl, P.M., Marcum, J.P. et al. Helping Others Shows Differential Benefits on Health and Well-being for Male and Female Teens. J Happiness Stud 10, 431-448 (2009).

22. Werner EE. 1992. The children of Kauai: resiliency and recovery in adolescence and adulthood. J. Adolesc. Health 13:262-68.

23. Wright, J., \& Mischel, W. (1982). Influence of affect on cognitive social learning person variables. Journal of Personality and Social Psychology, 43(5), 901-914. 